\title{
TRANSLATING A SCIENTIFIC TEXT INTO ENGLISH: COGNITIVE PERSPECTIVE
}

\author{
Alexey Minchenkov \\ Saint Petersburg State University, Russia \\ Phone:+79626820995, E-Mail: alexey.minchenkov@gmail.com
}

\begin{abstract}
Within the framework of Cognitive Translation Theory, the paper aims to explore how students of science who do not specialize in English use and acquire various kinds of knowledge in the process of translating a scientific text from Russian into English, focusing on the problems they encounter and the strategies they use in order to solve these problems. The study is based on the assumption that with the numerous sources of information available today many of the knowledge gaps both linguistic and non-linguistic can be filled provided the translator uses the right sources at the right moment. The paper uses data obtained from an experimental study carried out using the think-aloud protocols technique. The translation process is described in terms of the cognitive-heuristic approach to translation, using such terms as the cognitive context, cognitive search, and auto-correction. The paper uses the term 'operational error' to denote the wrong strategy employed by the translator, which leads to a breakdown in the process of translation and eventually to an unsuccessful translation variant. Various kinds of operational errors specific to students of science are discussed using examples from the protocols. Special attention is paid to the importance of translation on the conceptual level and the use of auto-correction to ensure the naturalness of the target text. The experimental data obtained also allow identifying the areas of English grammar that cause the most problems for students of science.
\end{abstract}

Key words: cognitive translation theory, cognitive-heuristic model, operational error, cognitive context, think-aloud protocols

\section{INTRODUCTION}

As Russian scientists are increasingly required to publish in foreign journals, the skill of producing research papers in English becomes very much sought-after in this country today. It appears that a large number of scientific papers in English written by Russian scientists and submitted for publication are in actual fact translations from Russian. Even when they are not first written in Russian and then actually translated into English, not infrequently by a translator who is not identical with the author and is a linguist, these papers tend to be 'translated', as it were, mentally, as the author does not directly verbalize his/her meanings in English, but first expresses his/her ideas in mental words in Russian and then, also mentally, translates these words into English. A typical problem with both kinds of translations is their bad quality. The latter is evidenced by numerous research reports in English that lack naturalness and sometimes, when meaning is obscured due to bad English, indeed confuse the reader. As is known, quite a lot of 
research papers submitted by Russian scientists are rejected by the journals because of their bad English. One question that arises in connection with the problem is what linguists can do to tackle it, or how linguistic research can contribute to improving the situation.

Over the past decades there have been tremendous changes in terms of access to sources of information. Whereas in the 1980s a Soviet translator from Russian into English could essentially only rely on his/her acquired knowledge of the source and target language, some bilingual dictionaries and books on translation, in today's Russia anybody, not only a linguist, can easily gain access to a great variety of Internet resources and dictionaries of different kind, which offer authentic samples of natural English. One of the major tasks facing the translator into a foreign language today is to learn to use the available resources effectively so as to fill whatever gaps he/she may identify in the process of translating and thus complement their body of knowledge. Therefore, teaching translation into a foreign language today should involve identifying the knowledge gaps that a particular group of students has and the skills they lack of filling these gaps, so that the necessary skills could then be developed, thus ultimately making a student an independent learner. The underlying hypothesis of the present study is that a large number of useful insights into the specific problems students encounter in the process of translation and the strategies they employ, both correct and incorrect, could be gained through using the think-aloud protocols technique.

\section{COGNITIVE STUdies OF THE TRANSLATION PROCESS}

\subsection{Cognitive Translation Theory}

The last decades have seen the rapid development of cognitive linguistics (Cruse, 2004; Jackendoff, 1996; Langacker, 1991, 1999; Lakoff, Johnson, 1999; Talmy, 2001) and what has been termed Cognitive Translation Theory (Rojo, Ibarretxe-Antunano, 2013: 18). Cognitive linguistics dealing as it does with the accumulation, processing and expression of knowledge through language and viewing language as "an integral part of cognition" and "a product of general cognitive abilities" (Rojo, Ibarretxe-Antunano, 2013: 11), provides a solid theoretical framework for translation studies and supports the idea that translation is not just a transfer from a SL text to a TL text or an "interchange of linguistic structures" but a process of mediation between "two different conceptual worlds" (Rojo, IbarretxeAntunano, 2013: 19). Within the cognitive framework, the research focus in translation studies is shifted from the product (normally required to be faithful to the source text) (Catford, 1965) to the process of translation, and the active role played in this process by an individual translator who processes a text in one language and creates a text in another language based on his/her own knowledge and experience of the world (Bell, 1993; Hatim, Mason, 1990, 1997; Langacker, 2008; Croft and Cruse, 2004). The body of knowledge that an individual translator possesses is referred to by some authors as an encyclopedic knowledge base (Halverson, 2013: 37]. An act of translation thus effectively consists in activating and selectively using different kinds of knowledge, including linguistic knowledge, that comprising the knowledge base. All of the different kinds of knowledge contribute to and constrain the process of translation (Halverson, 2013: 37). The encyclopedic knowledge base is specific to every particular translator (Halverson, 2013: 39 ), thus every process of translation becomes a unique creative act. 


\subsection{Think-Aloud Protocols Technique}

Since the 1990s studies of the translation process have involved the analysis of real translation data with the aim of describing translation strategies, recording translators' problems and solutions. At some point this kind of empirical studies began to include introspective experimental investigations of the translator's mental processes. To gain access to the translator's "black box", a method was developed that was taken from experimental psychology and named the Think-Aloud Protocol (TAP). The method consists in the translator verbalizing, as much as possible, his/her mental process while translating. Everything that is said by the translator is recorded, and the resulting protocols are then analyzed by the researcher. The technique could be combined with the filming of the participants' behaviour and sometimes their eye movements and pupils' dilations as a reflection of their mental activity (Rojo, Ibarretxe-Antunano, 2013: 9). Since the 1990s a large number of scholars have used the method in their experimental studies of the translation process, for various research purposes (Kussmaul, 1991; Lörscher, 1991, Kiraly, 1995, 1997; Dancette, 1997; Minchenkov, 2007, 2011). In our view, the experimental study of the translation process by means of TAPs offers a number of advantages. Besides revealing linguistic knowledge gaps, something that can be achieved by using other empirical methods, the analysis of TAPs allows one to identify other problems encountered by translators, those that have to do with non-linguistic knowledge gaps and a lack of some necessary skills. And since, as mentioned above, the cognitive approach to translation implies that every process of translation is a unique creative act, the problems identified will be specific to those translating and to the kind of translation performed (e.g. translation of a physical text from Russian into English), not just common problems encountered by anyone who translates any kind of text. By analyzing TAPs of the process of translation from Russian into English of a scientific text performed by different students of science a researcher can identify a range of problems that Russian scientists have when they translate from their native language into English. The results of such an analysis could later be used in teaching students of science to write research reports in English or to translate scientific papers from Russian into English, and also as useful material in writing course books.

\subsection{Cognitive-Heuristic Model of Translation}

The theoretical framework for our study was provided by the Cognitive-Heuristic model of translation developed within the more general cognitive framework (Minchenkov, 2007, 2011). The Cognitive-Heuristic model defines translation as "a heuristic process of verbalization by means of TL units of the conceptual structure formed in the translator's mind on the basis of a SL text" (Minchenkov, 2011: 160). Translation is seen as a special kind of communicative-cognitive activity, in which the decisive factor is access to and the interaction of different kinds of knowledge, both those that are already present in the translator's mind at the start of the process and those that are acquired in the process. A lack of relevant knowledge or failure to access or activate it at the right moment causes breakdowns in the translation process, which, in their turn, lead to wrong decisions, errors or even complete inability to successfully translate whole portions of the source text. Although the translation process is not linear but has a shuttle nature (Bell, 1993), one can roughly identify two main stages of the process - the building of a conceptual structure based on the source text and the verbalization of this structure in the TL. The most important mental operation in the first stage is termed as "cognitive search", whose ultimate aim is the formation of a coherent structure of 
concepts. The cognitive search involves the interplay in the translator's mind of structures of knowledge of the world, people and the source language and culture, which are collectively referred to as the "cognitive context" (Boldyrev, 2014: 119; Rojo, Ibarretxe-Antunano, 2013: 7 ), together with the knowledge acquired as the translator is analyzing the situation described in the text. The knowledge of the source language includes the SL worldview and the knowledge of the prototypical meanings of the words that make up the source text.

The second stage, the verbalization of the structure of concepts, also involves the interplay of different structures of knowledge, including the knowledge of the target language with its norms, worldview and the prototypical meanings of its items. The most important operations in the second stage are termed as "recombination of concepts", which consists in the rebuilding of the conceptual structure formed so that the concepts that eventually make it up may agree with those that constitute the meanings of TL items (Minchenkov, 2011: 126-127), and "auto-correction", the goal of which is the ultimate naturalness of the TT (Minchenkov, 2011: 170). Within the framework of the model, the resulting TL items that constitute the TT are termed "variants" not "equivalents". It should be noted that specific problems and breakdowns in the process of translation and, consequently, translation errors are, as a rule, closely linked to specific stages in the translation process, which the subsequent analysis of the protocols will show.

\section{ANALYSIS OF THE PROTOCOLS}

\subsection{Experimental Procedure}

Our experimental study involved six PhD students of Saint Petersburg State University, three of whom were students of physics and the other three students of chemistry. All the students could write and speak English at a rather advanced level, had over two years of experience in the translation of science texts from English into Russian, a little experience of translation from Russian into English and ample experience presenting and writing research reports in English. The students were asked to translate from Russian into English a physical text of approximately 2,000 characters on molecular machines. The text was taken from one of the issues of the Russian popular science magazine "Science and Life" and required a certain level of knowledge of chemistry and physics in general and molecular machines in particular. All the students were given the same instructions. We asked them to translate the text at home describing their actions and verbalizing everything that went through their minds during the experiment - their reflections, bits of translation, questions, hypotheses, intentions and so on, record themselves as they were doing so and type the final versions of their translations. The students were told that there was no time limit for the task and they could use whatever sources they thought necessary to use, which, in our view, contributed to the authenticity of the task. The participants were especially recommended to use dictionaries other than bilingual Russian-English ones. To show the students more vividly what they were expected to do, we translated a few sentences from another text in their presence and demonstrated the advantages of using some specific dictionaries, such as Oxford Collocations Dictionary and Cobuild Advanced Learner's Dictionary. When the students had completed the task, they submitted the audio files with the recorded protocols and the electronic versions of their translations. Thus the data collected in the experiment included the original Russian text, six typed variants of its translation and six audio protocols. 
The subsequent analysis of the protocols together with the final translation variants was performed after we translated the text ourselves and carried out an introspective analysis of our own actions and mental processes. The latter was an essential part of the study in that the cognitive-heuristic approach to translation implies that any assessment of any actions or decisions made by a translator should be carried out considering the possibilities that exist in the particular context in which the translation is made. And the assessor modeling the translation process in his/her own mind first prior to and then parallel to the assessing is an effective way to explore these possibilities. As stated above, the felicity of the translation process crucially depends of the translator's ability to use relevant knowledge and, when the knowledge is lacking, to gain access to it. The analysis of the protocols was performed based on the assumption that if some piece of knowledge was lacking but could be acquired through easily available sources, through analysis or inference on the basis of available knowledge (as was revealed by means of our introspective analysis), then the failure to do so through inaction or wrong action constituted what can be termed as "operational error". Operational errors lead to breakdowns, wrong decisions and ultimately unsuccessful translations. It is these operational errors that think-aloud protocols are especially effective in revealing.

\subsection{Conceptualizing the Source Text: Problems, Strategies and Errors}

When one is translating from one's native language into a foreign one, the first stage of the translation process, that is, the formation of a conceptual structure on the basis of the source text is quite often a rather straightforward operation as not much cognitive search is required. In this study, however, the analysis of the protocols showed quite a different situation. Three of the participants specialized in physics and, as the protocols revealed, were not very well acquainted with the phenomena and entities described in the text. Other two though specializing in chemistry did not know much about the particular topic of molecular machines and also had difficulty understanding a whole number of terms and phenomena. Only one participant had some knowledge of the subject matter discussed in the text. Therefore, what most of the participants needed was an extensive cognitive search with the aim of filling their knowledge gaps in the cognitive domain that the text dealt with. With the sources of information available today the most obvious strategy in this situation would have been to read first through the whole text paragraph by paragraph and using Internet resources, the widely known Wikipedia, for example, to try and understand what is described in it. This kind of strategy agrees with what is described by J. Dancette as working on the "conceptual" or "notional level", inquiring about the conceptual referents of words or word combinations, or about the relationships between the entities and phenomena described (Dancette, 1997: 94). Instead, five out of the six participants often worked on what Dancette termed the linguistic (lexical) or textual level (Dancette, 1997: 94), translating sentence by sentence or, not infrequently, even word by word and using Russian-English correspondences that they knew or Russian-English dictionaries when they did not know the English translations of Russian words. As a result, they sometimes failed to conceptualize not only portions of the source text that required specialized knowledge, but also those that did not.

Thus in the stage when the translator is expected to form a coherent conceptual structure based on the source text the following operational errors were observed - tendency to translate word for word, failure to conceptualize using the cognitive context, over-reliance on inter-lingual correspondences in one's memory, tendency to use bilingual dictionaries instead of sources providing conceptual information. As the analysis of the protocols shows, the operational errors mentioned impede the translation process not only in that they 
lead to breakdowns but also because they can cause the translator to waste time. Let us now consider a number of examples.

The translation of the introductory segment of the first sentence of the text Raboty $v$ oblasty sozdaniya moleculyarnych mashin is interesting for analysis for two reasons. First, it introduces the main term moleculyarniye mashiny, which is later used throughout the text. Second, the first four words of the segment represent the rather typical wordiness of the Russian language as in this particular context they all together effectively mean 'the development', so that the translation of the phrase should start with its conceptualization. As has been mentioned above, only one subject of the experiment, the translator $\mathrm{S}$, had knowledge about molecular machines and translated the Russian term by the English one almost straight away. The translators $\mathrm{J}$ and $\mathrm{M}$ did not know the concept but chose the right translation strategy. They suggested a hypothesis - "molecular machines", and then tested and proved it by means of the Wikipedia. The other translators made operational errors of varying degrees of gravity. The translator E, for example, first translated almost mechanically by "molecular engines" and did not test out his hypothesis. Then, as he was translating the second sentence, he came back to the term and changed it to "molecular machines" without giving a reason or testing out the new hypothesis. The variant happened to be correct, but remained untested, whereas it could have been tested and proved, as shown by J's protocol. The translator P first suggests the right variant "molecular machines", but then has doubts and, rather than testing his hypothesis in the Wikipedia, commits an error by looking up machines in a Collins Cobuild monolingual dictionary. He is not convinced by what the dictionary says, so he discards "machines" and suggests the wrong term "molecular devices", which later becomes his final translation variant.

The phrase Raboty $v$ oblasty sozdaniya was successfully conceptualized by the translator S and translated as "The synthesis". The translator J, who is unhappy with the English word "work", also tries to conceptualize the phrase and suggests the variant "design study", which, he believes, expresses the collective meaning of all the words in the Russian phrase. However, the variant belongs to a different cognitive domain. The other participants translate word for word, we found little or no evidence of attempts to conceptualize the phrase, and this is reflected in the translation variants suggested: "works in the field of (molecular machine) building", "investigations in the field of creation", "work in the field of creating", "work in area of (molecular machines) creation".

One of the central problems in the translation of the text was the conceptualization of the Russian unit Moleculyarnoye kol'tso v etych structurach nadeto na lineynuyu moleculu, mostly due to the contextual meaning of the Russian word nadeto, which is opaque to all who do not have specialized knowledge. To solve the problem, those who are not acquainted with the cognitive domain of molecular machines need to conduct a thorough search through relevant Internet resources in English. As the protocols of the translators $S$ and $\mathrm{P}$, as well as our own effort show, the necessary information can be found: in an English chemist's worldview the molecular ring is threaded over or onto a linear molecule. The translator $\mathrm{P}$, for example, finds in a relevant article not only the verb itself but also the preposition that is used after it. However, the other participants used different strategies that proved to be erroneous. The translator E started by looking the Russian word nadet' in a bilingual dictionary and found, predictably, "put on". Unhappy with the variant, he began to conceptualize the unit and came up with the Russian nanizano. He found an English correspondence for the latter word - "threaded", checked it in an Oxford dictionary and suggested "threaded through a linear molecule". He later discarded the variant because of 
"through", which, he said, did not agree with the words that followed, and fell back on his original variant "molecular ring is put on a linear molecule". The translator J relied on his knowledge of the English correspondence of the Russian verb nadet' and used it saying that even though he did not like the variant very much, he did not have time to test his hypothesis. The translators $\mathrm{M}$ and $\mathrm{N}$ just used what the Russian-English dictionary offered them.

Because of a lack of relevant knowledge of chemistry some of the participants also had difficulty conceptualizing segments of the text containing the Russian words soyedineniya (in ...pervymy eti soyedineniya sintezirovali nemetskiye fiziki ...) and stsepleniye (in $\mathrm{Na}$ pervom etape sinteza proischodit stsepleniye component ...). Two of them failed to solve the problems through the exclusive use of the bilingual dictionary. Thus the translator $\mathrm{M}$ encountering the word soyedineniya first suggested, wrongly, the English "bonds", then hesitated and decided to look up the Russian word in a Russian-English dictionary. He found "bonding" and "binding" and finally decided to use "bindings". When solving the same problem, the translator E had wasted time working with a Russian-English dictionary before it finally occurred to him to look in the Wikipedia for the names of the German scientists mentioned in the text, where he quickly found the right English word "compounds". However, the use of the wrong strategy ultimately prevented the translator E from solving the problem with the word stsepleniye. Instead of using relevant Internet resources for the name of the scientist mentioned, he again turns to a Russian-English dictionary, where he finds "cohesion" and "adhesion". Looking up the word "adhesion" in an Oxford monolingual dictionary, he seems satisfied and decides that it is a suitable variant. In the auto-correction stage, however, he again has doubts realizing that "adhesion" does not really describe what is going on, and turns one more time to a Russian-English dictionary looking up the entry for the verb stseplyat'. Surprisingly, he pays no attention to the English verb "couple", which would have been the right choice, but opts instead for "bonding", remarking that it should be suitable for all occasions. In a similar fashion, the translator P fails to solve the problem of conceptualizing the Russian stsepleniye as he goes through a list of English correspondences to the Russian verb stseplyat' in a bilingual dictionary. He finds "clutch", "adhere", "connect" and "join", but dissatisfied with all of these suggests his own "unite" and finally opts for it.

\subsection{Constructing the Target Text: Problems, Strategies and Errors}

\subsubsection{Naturalness in Translation}

In the second stage of the translation process, one of the crucial factors is the ability of the translator to find target language items that would verbalize in the most natural way the meanings that constitute the conceptual structure. Naturalness is defined in the Dictionary of Translation Studies as "the extent to which a translation is expressed in clear, unforced terms in the TL" (Shuttleworth \& Cowie, 1999: 111). Achieving naturalness is often problematic in that the meanings that find their way into the conceptual structure and the relationships that are established between these meanings are largely influenced by the SL world view and image schemas. Having formed the conceptual structure, the translator often finds that some of the meanings in it cannot be expressed in the TL as they are, while others if verbalized as they are and in the order in which they are arranged in the conceptual structure will give TL items and structures that sound unnatural in the given context. To solve the problem, the translator has to restructure or recombine the meanings (at the conceptual level) and/or perform auto-correction (at the target text level). Both the 
recombination of meanings and auto-correction are performed in respect of the TL meanings, worldview and image schemas. When one is translating into a foreign language a major problem is that the translator may just not know how a particular meaning is naturally expressed in the TL or how TL as a whole organizes meaning in a particular cognitive domain. However, as has been mentioned above, with the multiple sources of information available today the problem of lack of relevant knowledge can often be successfully resolved.

When, as described above, a translator had failed to conceptualize some fragment of the source text, which meant that a coherent structure of concepts had not been formed, we observed literal translation by means of a bilingual dictionary or ready inter-lingual correspondences present in the translator's memory, which more often than not led to an unnatural final variant. However, the analysis of the protocols shows that the participants also encountered problems when they had actually managed to conceptualize a fragment. The problems were predictably of two kinds - lexical and grammatical. The former could often be resolved by using the right sources.

\subsubsection{Lexical Problems}

There are a number of sources that one can use in the process of translation to fill the gaps in one's knowledge of the target language, its norms and world view. These include a variety of monolingual dictionaries of the language, especially so called learner's dictionaries, collocations dictionaries, dictionaries of synonyms or thesauri, language databases and corpora, and Internet sources like the above-mentioned Wikipedia. The analysis of the protocols shows that most of the kinds of sources, with the notable exception of corpora, were actually used by all the participants, albeit with a varying degree of frequency and effectiveness. The problem was that they were used inconsistently, or incorrectly, or after a fairly large amount of time had been wasted. A vivid example of an incorrect use of the sources available is the protocol of the translator J. It should be noted that on the whole $\mathrm{J}$ has a rather good command of the English language, is knowledgeable about science terminology and well-read. At the very beginning of his work on translation he lists a number of sources that he is going to use, and these include, besides a bilingual dictionary, a monolingual dictionary, a dictionary of synonyms, Wikipedia and an Internet resource, which gives words in real contexts of use. To solve problems he often employs correct strategies, like proposing and then testing hypotheses using the right sources. Thus, for example, he effectively uses Internet resources and a monolingual dictionary to find English variants that sound natural in the given context, like "derivatives" for the Russian proizvodniye, "subsequently" for vposledstviyi, "compounds" for soyedineniya and "coupling" for stsepleniye. At the same time the analysis of the protocols shows that he sometimes employs incorrect strategies, which lead him to unfortunate mistakes. For example, when one is translating the ST segment sozdaniyi nanorazmernich mashin, the problem of choosing the right verb to collocate with the English word "machines" can be easily solved using Oxford Collocations Dictionary. However, when J has doubts about whether machines can be created, he does not use a collocations dictionary but instead looks up the word "creation" in a dictionary of synonyms, finds a number of nouns like "invention", "production" and "setting up", and finally opts for the latter, which gives him a phrase that sounds very clumsy in the given context - "setting up of nano-size machines". In a similar fashion, when he is translating the Russian $v$ ochen' nebol'shych kolichestvach, J first proposes the right hypothesis "in very small amounts", but rejects it without a valid reason and formulates 
another hypothesis "the outcome was very small". The word "outcome" is not checked in a monolingual dictionary, and the participant does not realize that it does not fit into the context, which deals with the synthesis of compounds and the amounts that are synthesized. There are other operational errors of this kind when $\mathrm{J}$ does not use a monolingual dictionary or a collocations dictionary when necessary.

As evidenced by the protocols, failure to use a collocations dictionary and a tendency to use a largely irrelevant source like a Russian-English dictionary is one of the most frequent operational errors committed by the participants. First, it is a collocations dictionary and not a Russian-English one that normally helps when one is searching for a verb to go with a particular noun. A good example is the translation of the verb manipulirovat' in the ST segment manipulirovat' strukturoy i svoystvamy molecul. The protocol of the translator S shows that the right English verbs - "alter" and "modify" - can be found for the noun "properties" in a collocations dictionary. However, most of the other participants did not use one and came up with "manipulate". Similarly, the translators P, M and N did not realize that approaches or methods cannot be offered, they are suggested, and did not use a collocations dictionary to help them. Most of the participants did not use a collocations dictionary when translating the Russian otkryl put' ( $k$ polucheniyu) and used the wrong variant "opened the way to" instead of "paved the way for". A collocations dictionary would also have been useful in finding the correct prepositions: "in the first stage" instead of "on the first stage" (translators E, P, M), "at the end of the 1970s" instead of "in the end of the 1970s" (translators E, M, N). Sometimes the participants just did not know how to use a collocations dictionary properly. For example, the translator P when searching for a verb to go with the English noun "properties" looked at the entries for the verbs "govern" and "control", rather than the entry for the noun "property" itself.

One of the most frequent operational errors was the use of a Russian-English dictionary instead of a monolingual dictionary or an Internet resource or language corpus and without testing the variants found in a Russian-English dictionary in other sources. Thus the translator E proposes the English verb "merge" as a hypothesis for the Russian sobiratsya in mogut sobiratsya samostoyatel'no, and this hypothesis is not examined in a monolingual dictionary. Likewise the translator $\mathrm{N}$ found the English "surrogates" for the Russian (obyemistiye) zamestitely in a Russian-English dictionary, and it did not occur to him to look up the word "surrogate" in a monolingual dictionary. If he had, he would probably have realized that the English word means something very different from what is meant in the ST. The translation of the Russian items (obyemistiye) zamestitely and (obrazuyut tsentralny) uzel posed a problem for all the participants, and this is the kind of problem that could only be solved if the translator found relevant Internet materials dealing with catenanes and rotaxanes. The items in question have a large number of different contextual meanings, which is by necessity reflected in bilingual dictionaries. When a translator uses only a bilingual dictionary for the translation of such items, and even when the bilingual dictionary is complemented by a monolingual dictionary, the translation process almost certainly ends in a failure, as the protocols of the participants $\mathrm{J}, \mathrm{P}, \mathrm{E}, \mathrm{N}$ and $\mathrm{M}$ show. Internet resources were also very useful for finding relevant adjectives like "cyclical", "ring-shaped", "nanoscale" and "multiple ring" for the Russian tsyklicheskiye, koltseobrazniye, nanorazmerniye and mnogouzelkoviye, respectively. Those participants who used the Internet in the first place were able to find the English items quickly, the others either wasted time or failed altogether. 
A monolingual dictionary is an important source of information about the language and its world view, something that is often ignored by students, especially those who are not linguists. Our protocols show that some of the problems that the participants mulled over could have been easily solved if they had used a monolingual dictionary. For example, the translator E when struggling with the Russian segment moleculy sposobny $k$ samosborke began to wonder if the English adjective "capable (of)" could be used with inanimate subjects. He spent some time over it and finally decided that it probably could not. However, as, for example, the Cobuild Advanced Learner's dictionary shows, the adjective can follow both animate and inanimate subjects (CALD, 2014: 219). Similarly, the translator M when mulling over whether to use an article before the noun "synthesis" wondered if it was countable. He finally decided, without much certainty, that it should be. But then the answer could have been found much quicker as the same dictionary classifies the noun in question as variable (CALD, 2014: 1587).

\subsubsection{Grammatical Problems}

The protocols have also revealed gaps in the knowledge of English grammar that were a frequent source of problems for the participants, causing them either to waste time or to make mistakes in constructing the sentences in the target language. By extension, these problems could be considered typical of students of science for whom the English language is not their main specialty. Interestingly, as can be shown by the protocols, in many cases it was not as if the students were completely unaware of the relevant grammar rules. The problem often was that they forgot, or remembered only part of the relevant rule, or were not sure and dithered, or applied the rules inconsistently or intuitively. The most difficult area of grammar was predictably the articles. Many of the participants from time to time chose to use no article before singular countable nouns, some of them after a little consideration, which clearly suggests a lack of relevant knowledge as the participants could not apply the necessary criteria to confirm their hypothesis. For example, the translator P pondered over whether to use the indefinite article before the noun "approach" in "suggested (a) supramolecular approach" and decided against it showing no evidence of the knowledge of the rule and relying exclusively on his intuition. Many problems and mistakes were caused by a lack of knowledge of what can be termed as the cataphoric definite article, the anaphoric and indirect anaphoric definite article (Biber et al, 1999: 263-264), the use of the definite article before a common noun modified by a proper noun and the use of the articles before newly introduced entities. The protocol of the translator $J$ is a good illustration of these problems, the more so as one can hear him reflecting about the use of the articles more often than the others.

In the second sentence of the ST beginning with Issledovaniya bazirovalis' na idée $o$ tom, chto... the word Issledovaniya refers back to what has previously been mentioned in the first sentence. This is anaphoric reference. The translator J suggesting the English translation variant "Investigations" first uses it without any article. Later he comes back to it and starts reflecting about whether he should use the definite article before the noun. As a result of these reflections he wrongly decides that he should not as those are not concrete investigations. The protocol thus demonstrates that the student cannot apply the right criterion and does not see the referential link between the two sentences.

Another interesting example is connected with the ST segment Moleculyarnoye kol'tso $v$ etych strukturach nadeto na lineynuyu moleculu. The exact term Moleculyarnoye kol'tso is not mentioned in any of the previous sentences, but the preceding description of the structure 
of molecular machines makes it clear that the molecular ring is an essential part of this structure. The connection between the molecular ring and the preceding description although not signaled by word repetition is nevertheless inferred and we are dealing with indirect anaphoric reference. Consequently, the English translation variant should be used with the definite article. The translator $\mathrm{J}$, however, does not see the connection and after some hesitation suggests "In this architecture a molecular ring is put on a linear molecule".

The TT that the translator $\mathrm{J}$ is constructing many instances of cataphoric reference, which is established through some noun modifier, like an of-phrase, that follows later in the text (Biber et al, 1999: 264). When there is cataphoric reference, the noun modified is normally used with the definite article. The translator $\mathbf{J}$ apparently does not know it as there is no evidence in the protocol of him reflecting in terms of cataphoric reference, and both the protocol and the typed version of his translation demonstrate examples like "they serve as building blocks for a design of various nanomachines", "one can manipulate a structure and properties of molecules", "a supramolecular approach to a synthesis of catenanes and rotaxanes".

The translator $\mathrm{J}$ also demonstrates an inconsistent and intuitive use of the definite article before a common noun modified by a proper noun. On the one hand, he uses the definite article in the TT segment "The ... Nobel laureates J.P.Sauvage and J.F.Stoddart". On the other hand, there is no article before "German chemists Schill and Luttringhaus". Another problem for the translator $\mathrm{J}$ is the use of the articles before newly introduced entities. When he comes to the sentence "Rotaxanes ... became the next step towards...", he starts mulling over the use of the article before the word "rotaxanes" obviously unaware that it performs the function of the rheme and, being plural, should be used without an article. He frankly admits that he does not know how to solve the problem of the article and eventually uses no article intuitively.

The protocols also show that the participants had problems with other areas of grammar. Thus many of the students demonstrated a lack of knowledge of the use of the Present Perfect and the Past Simple Tenses, which, in the case of some of them, came as a surprise. For example, the translator $M$ working on the ST segment pervymy eti soyedineniya sintezirovali nemetskiye khimiki does not realize that the situation described belongs to the past and decides to use the Present Perfect Tense in the translation of the verb sintezirovali. Interestingly, he later revisits the tense, only to confirm his original hypothesis, giving as a criterion the fact that it happened for the first time. The criterion as cited by the student is definitely invalid and leaves one wondering where it could have been taken from. The participant then goes on to use the Present Perfect of all the other verbs in the English variant, even though the whole sentence evidently describes a past situation which has since changed. The example apparently demonstrates not only a lack of knowledge of the tenses but also a lack of proper conceptualization of the situation described. The translator $\mathrm{E}$ working on the same segment chooses the right tense but after some hesitation. Before that, when translating the first sentence of the text, which has an explicit Past Simple marker, the definite time adverbial $v$ kontse semidesyatych godov proshlogo veka, the translator $\mathrm{E}$ also has doubts and makes a telling remark that he has problems with the use of the tenses.

As the analysis of the protocols shows, the students often do not see the difference between the use of the modal verbs can, could and may. The translators $\mathrm{E}, \mathrm{N}$ and $\mathrm{P}$, for example, openly admit it. Another persistent problem is the position of attributes. Some of the participants placed long attributes in pre-position so that in the final translation variant we found segments like "various in structure and composition compounds" (translators E 
and P) and "freely moving relative to each other molecules" (translators $\mathrm{M}$ and N). The protocols show that the translators do not see such structures as a problem and do not correct them even when they revisit the segments in the auto-correction stage. Also observed was a tendency to place participle II denoting a dynamic action before the noun modified. Examples of this kind include "offered methods" instead of "methods suggested" and "developed methods" instead of "methods developed". Besides, some of the participants confused participle I and participle II in the function of an attribute. For instance, the translator P used "* phenanthroline-contained catenanes" instead of "phenanthroline-containing catenanes".

\subsubsection{Auto-Correction in Translation}

As has been mentioned above, an important factor in the translation process is the translator's ability to perform auto-correction. Failure to do so leads to unnatural-sounding TT segments, wordiness and spelling mistakes. A good example to show the importance of auto-correction is the translation of the ST segment Katenanamy nazyvayutsya khimicheskiye struktury, predstavlyaiutchiye soboj tsepochki...molecul. The translator J, whose first hypothesis, as the protocol shows, was a literal word-for-word translation "Catenanes are called chemical structures representing chains of... molecules", quickly realized that the structure sounded unnatural and grammatically wrong in English, and that English normally used different structures for giving definitions. Consequently, he suggested another variant, one that sounded like a typical English definition: "A catenane is a chemical structure consisting of chains of ...molecules". The translator E working on the same segment first suggested "By catenanes the chemical structures are called that...", then remarked that it did not sound good and put forward "By catenanes one calls chemical structures which...". Unfortunately, he did not go further, even in the auto-correction stage, which in his case was a separate stage that came after the whole text had been translated.

The protocols show that the participants chose unnatural variants as final and did not correct them further either because they did not know more natural-sounding English variants and sometimes did not even realize that they existed, or because they were too dependent on the ST, or because they just neglected to correct. For example, several of the participants did not check the spelling of the proper names or the names of the structures like catenanes or rotaxanes on the Internet and the typed final variants of their translation contained items like "*cetenanes", “*rotaxenes", "*Fraiburg" (instead of "Freiburg"), "*Sovage" (instead of "Sauvage"). Most of the students did not know that the meaning of the Russian segment $v$ kontse semidesyatych godov proshlogo veka could be naturally expressed in English by "in the late 1970s" and suggested clumsy phrases like "in the end of 70 s of the previous century" or "in the late 70s of the last century". Many of the participants struggling to translate the Russian osutchestvit' zamykaniye vtorogo tsykla wasted time mulling over the verb to collocate with "closing" and finally used either "fulfill closing" or "perform closing", whereas the most natural variant, which was suggested, for example, by the translator S, would have been "to close (the second ring)".

\section{CONCLUSION}

To conclude, the analysis of the protocols has shown, first, that with the sources of information available today it is possible for a scientist to successfully translate a scientific text from Russian into English provided he/she has mastered the basics of 
English grammar and uses correct translation strategies and sources to fill the gaps in his/her knowledge (both linguistic and non-linguistic) that are revealed in the process. Second, the protocols have demonstrated the most typical operational errors committed by non-linguists when they are translating from Russian into English, which prevent them from finding relevant knowledge when necessary and cause breakdowns in the translation process, ultimately leading to unsuccessful translations. These operational errors include failure to conceptualize the text as a whole using the cognitive context and sources of conceptual information, a tendency to translate word for word and preserve the grammatical word class and structures of the ST, over-reliance on inter-lingual correspondences in one's memory, a tendency to use bilingual dictionaries instead of sources providing conceptual information, failure to use monolingual dictionaries, collocations dictionaries, thesauri or language corpora when required by the situation, and failure to make auto-correction. Third, the analysis has revealed areas of English grammar that are the most frequent sources of problems for scientists producing a scientific text in English. Our study has also demonstrated the effectiveness of using think-aloud protocols for investigating the process of translation with the aim of identifying the problems translators face and the strategies they employ in order to solve these problems.

\section{REFERENCES}

Bell R.T. 1993. Translation and Translating: Theory and Practice. London: Longman.

Biber D., Johansson S., Leech J., Conrad S., Finegan E. 1999. Longman Grammar of Spoken and Written English. London: Pearson Education Limited.

Boldyrev N.N. 2014. The Role of the Cognitive Context in the Interpretation of the World and Knowledge of the World. The Herald of Cheljabinsk State University. Philology. Art Criticism. №6 (335). Issue 88: pp.118-122.

Catford J.C. 1965. A Linguistic Theory of Translation. London: Oxford University Press.

Croft W., Cruse A. 2004. Cognitive Linguistics. Cambridge: Cambridge University Press.

Cruse A. 2004. Meaning in Language. An Introduction to Semantics and Pragmatics. Oxford: Oxford University Press.

Dancette J. 1997. Mapping Meaning and Comprehension in Translation. Theoretical and Experimental Issues. Cognitive Processes in Translation \& Interpreting. J.H.Danks et al. (ed.). California: Sage Publications, pp.77-103.

Halverson S.L. 2013. Implications of Cognitive Linguistics for Translation Studies. Cognitive Linguistics and Translation. Rojo A. \& Ibarretxe-Antunano I. (ed.). Berlin: De Gruyter Mouton, pp.33-73.

Hatim B., Mason I. 1990. Discourse and the Translator. London: Longman.

Hatim B., Mason I. 1997. The Translator as Communicator. London: Routledge.

Jackendoff R. 1996. Languages of the Mind. Essays on Mental Representation. Cambridge, Massachusetts: the M.I.T. Press.

Kiraly D.C. 1995. Pathways to Translation: Process and Pedagogy. Kent: Kent State University Press.

Kiraly D.C. 1997. Think-Aloud Protocols and the Construction of a Professional Translator Self-Concept. Cognitive Processes in Translation \& Interpreting. J.H.Danks et al. (ed.). California: Sage Publications, pp.137-160. 
Kussmaul P. 1991. Creativity in the Translation Process: Empirical Approaches. Translation Studies: The State of the Art: Proceedings from the First James S Holmes Symposium on Translation Studies. van Leuven-Zwart K. \& Naaijkens T. (ed.). Amsterdam: Rodopi, pp.91-101.

Lakoff G., Johnson M. 1999. Philosophy in the Flesh. New York: Basic Books.

Langacker R. 1991. Concept, Image and Symbol. The Cognitive Basis of Grammar. Berlin: De Gruyter.

Langacker R. 1999. Grammar and Conceptualization. Berlin: De Gruyter.

Langacker R. 2008. Cognitive Grammar: A Basic Introduction. Oxford: Oxford University Press.

Lörscher W. 1991. Thinking-Aloud as a Method for Collecting Data on Translation Processes. Empirical Research in Translation and Intercultural Studies. TirkkonenCondit S. (ed.). Tübingen: Gunter Narr Verlag, pp.67-77.

Minchenkov A.G. 2007. Cognition and Heuristics in Translation Process. Saint Petersburg: Anthology.

Minchenkov A.G. 2011. Cognitive-Heuristic Model of Translation. Theoretical Foundations, Verification and Application. Saarbrücken: Lambert Academic Publishing.

Rojo A., Ibarretxe-Antunano I. 2013. Cognitive Linguistics and Translation Studies: Past, present and future. Cognitive Linguistics and Translation. Rojo A. \& IbarretxeAntunano I. (ed.). Berlin: De Gruyter Mouton, pp.3-30.

Shuttleworth M., Cowie M. 1999. Dictionary of Translation Studies. Manchester: St Jerome Publishing.

Talmy L. 2001. Toward a Cognitive Semantics. Vol. 2. Typology and Process in Concept Structuring. Cambridge, Massachusetts: the M.I.T. Press.

\section{SOURCES}

CALD 2014 - Cobuild Advanced Learner's Dictionary. Glasgow: HarperCollins Publishers. Oxford Collocations Dictionary for students of English. 2012. Oxford: Oxford University Press.

Nauka i zhizn'. (Science and Life). 2016. №12. 